\title{
NEW INSIGHTS INTO THE REENTRY BEHAVIOR OF DEUTERATED DCNQI Cu-SALTS BY MICROWAVE MEASUREMENTS
}

\author{
S. Predak, H.W. Helberg \\ Third Physical Institute, University of Göttingen, Germany \\ AND J.U. VON SCHÜTZ \\ 3. Physical Institute, University of Stuttgart, Germany
}

The microwave conductivity of the copper salt of DCNQI (N,N'-Dicyanoquinodiimine) with two methyl side groups (undeuterated, $h_{8}$ ), the fully deuterated salt $\left(d_{8}\right)$, the salt with only the methyl groups deuterated and of alloys of undeuterated and deuterated salts was measured. The microwave conductivity $(10.2 \mathrm{GHz})$ qualitatively follows the dc conductivity. The difference is in the window of diminished conductivity between phase transition and reentry, where the microwave conductivity is higher than the dc conductivity. This indicates the existence of a crystal fraction with higher (metallic) conductivity (portion: $\approx 1 \% 0$ ) not seen by dc methods.

PACS numbers: $72.80 . \mathrm{Le}, 72.60 .+\mathrm{g}, 78.70 . \mathrm{Gq}$

\section{Introduction}

The methyl substituted DCNQI copper salt $\left(h_{8}\right)$ behaves metallically down to low temperatures [1]. Salts with deuterated methyl groups $\left(d_{6}\right.$ and $\left.d_{8}\right)$ show sharp phase transitions from metallic to semiconducting behavior during cooling. The alloy $h_{8}: d_{6}=70 \%: 30 \%$ exhibits a phase transition, too, but during further cooling a reentry in the metallic state. This goes along with a giant hysteresis between cooling and heating. The present paper deals with microwave measurements on these compounds.

\section{Experimental}

Between 4 and $300 \mathrm{~K}$ we measured the microwave conductivity at $10.2 \mathrm{GHz}$, using a cylindric cavity, where the needle-like sample (typical length: $4 \mathrm{~mm}$, cross-section: $50 \mu \mathrm{m} \times 50 \mu \mathrm{m}$ ) was placed in the maximum of the electric field [2].

We investigated the undeuterated and two deuterated dimethyl DCNQI copper salts: 


\section{$\left(2,5-\mathrm{DCH}_{3}-\mathrm{DCNQI}\right)_{2} \mathrm{Cu}\left(h_{8}\right)$, \\ $\left(2,5-\mathrm{DCD}_{3} \text {-DCNQI }\right)_{2} \mathrm{Cu}\left(d_{6}\right)$, \\ (3-D,6-D,2,5-DCD ${ }_{3}$-DCNQI $)_{2} \mathrm{Cu}\left(d_{8}\right)$.}

In addition, three alloys of $h_{8}$ and $d_{6}$ with $90 \%, 70 \%$ and $50 \%$, respectively, of $h_{8}$ were investigated (in the following named as $(90: 10),(70: 30)$ and (50:50)). Moreover, we measured the conductivity of a $d_{6}$-salt, containing $30 \%$ lithium in its copper stack.

\section{Results and discussion}

At room temperature, all examined salts have a metallic conductivity of $10^{2}-10^{3} \mathrm{~S} / \mathrm{cm}$, which increases during cooling. The $h_{8}$-salt (Fig. 1) and the alloy

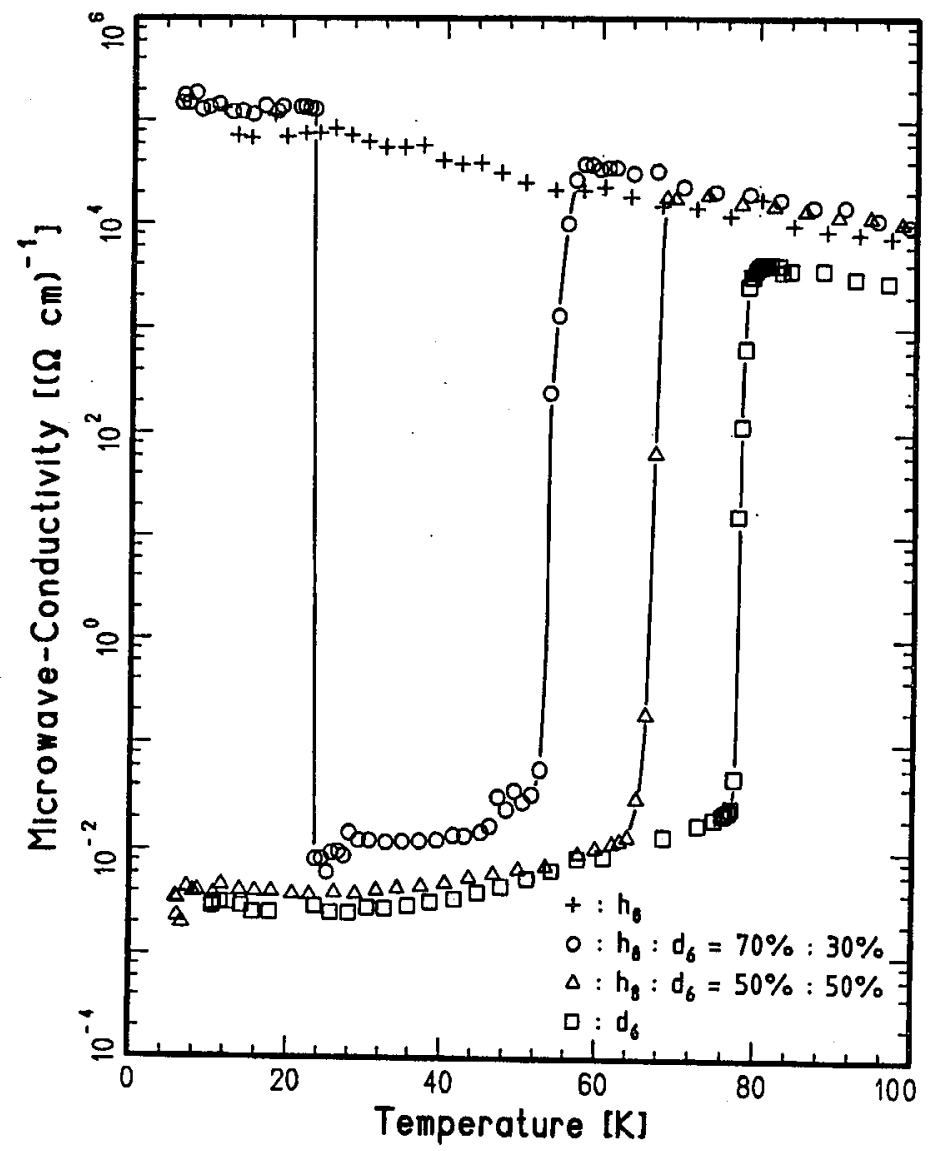

Fig. 1. Microwave conductivities of $h_{8}, d_{6}$ and the alloys (70:30) and (50:50) in the temperature range of $0-100 \mathrm{~K}$. 


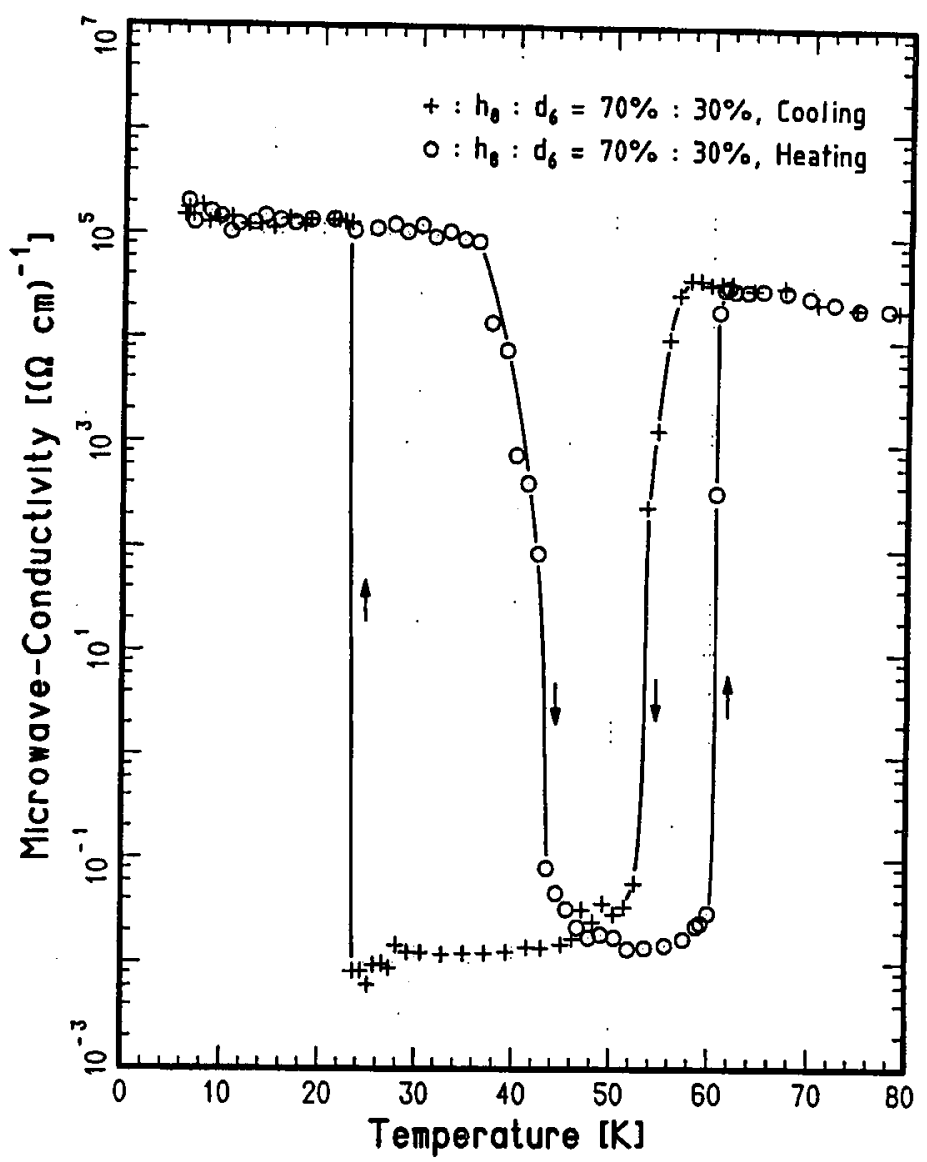

Fig. 2. Reentry and hysteresis in the microwave conductivity of the alloy $(70: 30)$; cooling and heating curve between 0 and $80 \mathrm{~K}$.

with the highest $h_{8}$-part $(90: 10)$ are metals down to $4 \mathrm{~K}$, where they reach about $10^{5} \mathrm{~S} / \mathrm{cm}$.

All other salts exhibit sharp phase transitions with a drop of conductivity of 5-6 magnitudes (Fig. 1). The transition temperature increases with the portion of deuterium from $53 \mathrm{~K}(70: 30)$ to $85 \mathrm{~K}\left(d_{8}\right)$. During further cooling all salts show a slight drop of conductivity. $d_{6}, d_{8}$ and (50:50) reach a conductivity of $10^{-3}-10^{-2} \mathrm{~S} / \mathrm{cm}$ around $10 \mathrm{~K}$. The alloy $(70: 30)$ on the other hand exhibits a sharp reentry phase transition into the metallic state at $24 \mathrm{~K}$ (Figs. 1 and 2). The value of about $10^{5} \mathrm{~S} / \mathrm{cm}$ is kept down to $4 \mathrm{~K}$. This behavior is accompanied by a large hysteresis.

In dc measurements [1], the reentry is also seen in the alloy (50:50) (Fig. 3). The dc phase transition temperatures and the conductivities in the region of metallic behavior are comparable to the microwave values (Figs. 3 and 4). Slight differences are possible as not the same samples were used. 


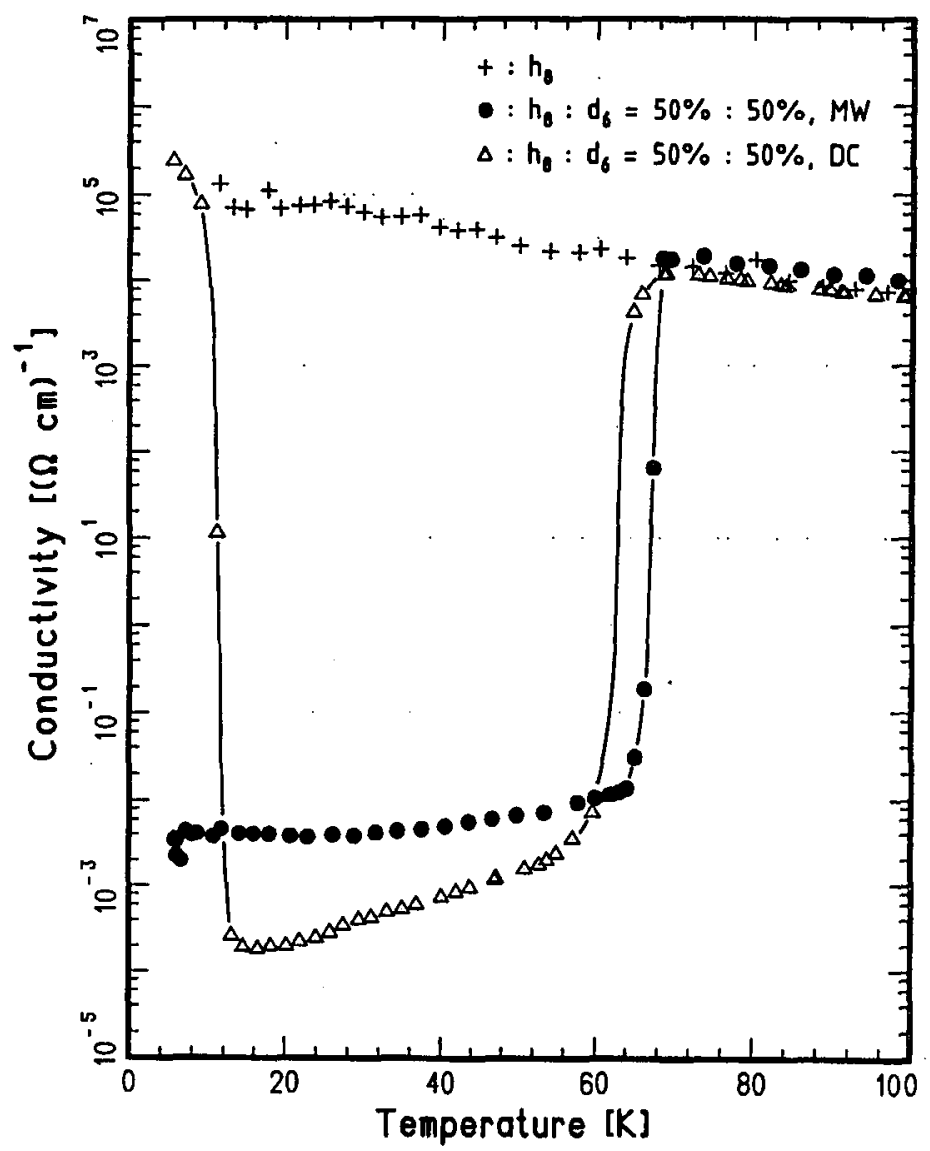

Fig. 3. Microwave conductivity of $h_{8}$ and (50:50) and dc conductivity of (50:50) (from [1]) in the temperature range of $0-100 \mathrm{~K}$.

In the low-conductivity region, however, the microwave values are higher for $d_{6}$ and the alloys (70:30) and (50:50). This is a hint for the existence of highly conducting areas even in the low conducting region. As their volume part undergoes the percolation threshold, they cannot be detected by dc measurements. Assuming a volume part of $1 \%_{0}$, the microwave conductivity of $d_{6}$ and (70:30) can be calculated, using the mixing formula of Maxwell-Wagner [3].

The $d_{6}$-salt with a lithium-alloyed copper stack shows similar microwave and dc conductivities [1]: a smoothened phase transition, shifted to higher temperatures.

Moreover, we tried to measure the conductivity perpendicular to the needle axis in the alloy $(70: 30)$, placing the sample in the maximum of the magnetic field of a cavity. The anisotropy could only be estimated to be 60 at room temperature and 300 at $80 \mathrm{~K}$. These values correspond to measurements of $h_{8}$ [4]. 


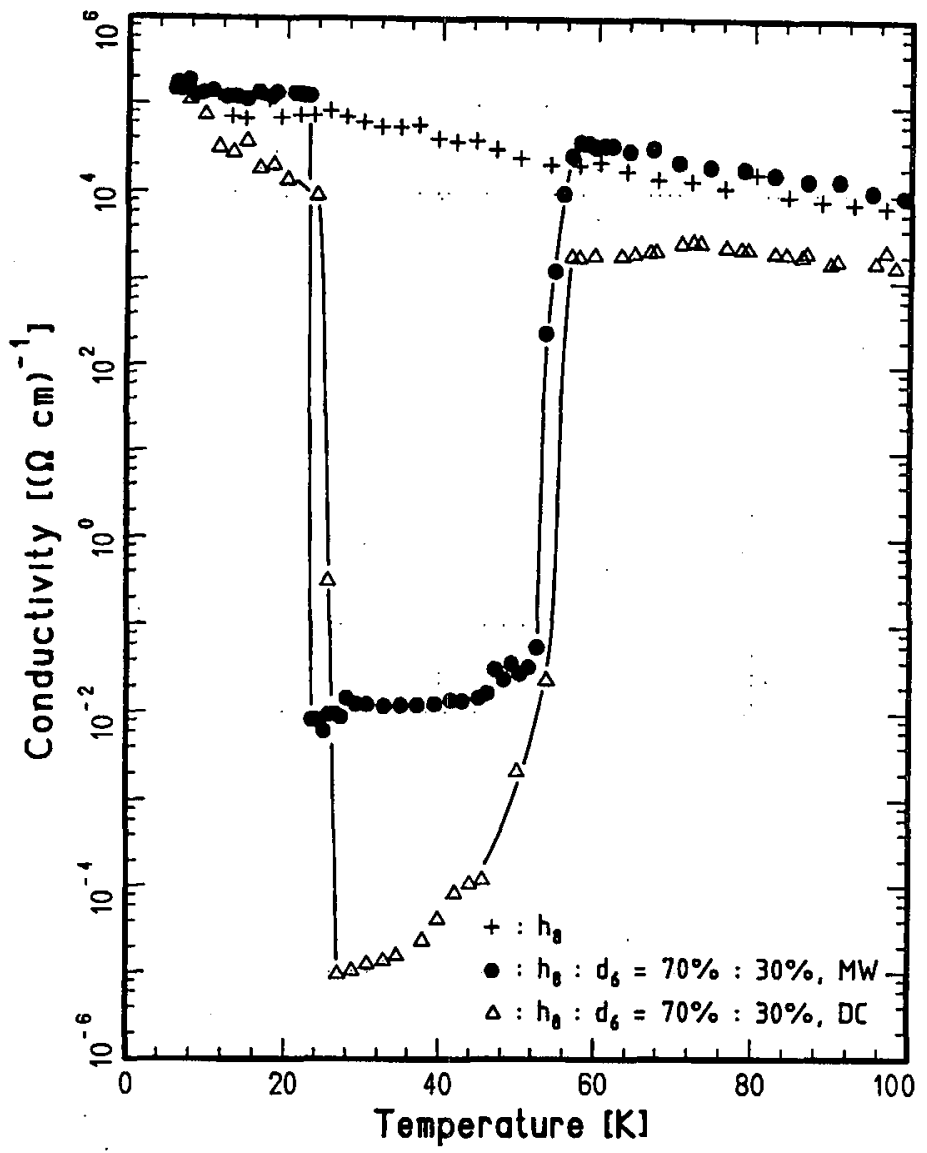

Fig. 4. Microwave conductivity of $h_{8}$ and (70:30) and dc conductivity of (70:30) (from [1]) in the temperature range of $0-100 \mathrm{~K}$.

\section{References}

[1] D. Bauer, J.U. von Schütz, H.C. Wolf, S. Hünig, K. Sinzger, R.K. Kremer, Adv. Mater. 5, 829 (1993).

[2] G. Schaumburg, H.W. Helberg, J. Phys. III (France) 4, 917 (1994).

[3] C.J.F. Böttcher, P. Bordewijk, Theory of Electric Polarization, Elsevier, Amsterdam 1978.

[4] R. Burkert, H.W. Helberg, J.U. von Schütz, Synth. Met. 55-57, 2519 (1993). 